\title{
Multicultural Arts and Integrative Medicine: Empowering Refugees in the Healing Process
}

\author{
Narayan Gopalkrishnan
}

\author{
James Cook University
}

\begin{abstract}
Refugees are people who move involuntarily from their country of residence often witnessing disasters, wars and the deaths of immediate family members prior to fleeing. In each of these instances, refugees experience traumatic situations that provoke strong reactions and emotions. This is often exacerbated by difficult refugee processing systems, detention and waiting in refugee camps, all of which make migration patterns and settlement processes for refugees are very different from those of other migrants. The psychological effects of the trauma experienced by refugees tend to be enduring and long-lasting. This paper explores the link between refugee mental health and wellbeing and multicultural arts in the tropics. The contention of the paper is that multicultural arts allows for sensitivity to a person's identity, heritage and experience and is an important component of healing and well-being. The paper uncovers how multicultural arts enable a dialogue around issues with forced migration, powerlessness, humiliation and anger and promotes social inclusion and belonging. The paper concludes by arguing that multicultural and multidimensional approaches are needed to achieve an integrated approach to the mental health of refugees.
\end{abstract}

\section{Introduction}

$\mathrm{T}$ he 1951 United Nations Convention relating to the Status of Refugees (UNHCR Convention and Protocol Relating to the Status of Refugees 14) states that a refugee is a person who:

owing to a well-founded fear of persecution for reasons of race, religion, nationality, membership of a particular social group or political opinion, is outside the country of his nationality and is unable or, owing to such fear, is unwilling to avail himself of the protection of that country; or who, not having a nationality and being outside the country of his formal habitual residence as a result of such events, is unable or, owing to such fear, is unwilling to return to it.

Complex Humanitarian interventions including political violence, natural disasters, and environmental degradation, are often the causes of the movements of refugee populations (Kneebone and Allotey). The majority of refugees tend to stay within neighboring countries, over $80 \%$ of them staying within the same region as their home country, while a few are resettled, through the work of the United Nations High Commission for Refugees, to countries that have agreed to accept them. At any one point, there are over 10 million refugees across the world, and many more that are displaced from their homes but are still within the country of origin (UNHCR Unhcr Statistical Yearbook).

Australia is one of the countries in which refugees are resettled through the UNHCR's programs, based on the fact that Australia has ratified the 1951 United Nations Convention relating to the Status of Refugees and has also acceded to the 1967 Protocol relating to the Status of Refugees in 1973. Under the Humanitarian Program, Australia has been resettling 
around 13,000 refugees every year over the last decade, which was expanded to 20,000 places in 2012 (DIAC Australia's Humanitarian Program 2013-2014 and Beyond). The refugees who resettle in Australia come from different parts of the globe, including those from the African nations, Middle Eastern nations, East European, as well as from South Asian and South-East Asian countries. Their health is often dramatically impacted on by the process of displacement and the subsequent journey (VFST).

Refugees face physical hardships, emotional trauma, torture and deprivation, often witnessing disasters, wars and the deaths of immediate family members prior to fleeing (Babacan and Gopalkrishnan; UNHCR The State of the World's Refugees). Many refugees also suffer torture, either within state systems or in other, more unregulated situations. The Victorian Foundation for the Survivors of Torture reports that more than 7 out of 10 refugees routinely undergoing health assessments reported having experienced psychological or physical violence of some kind (VFST). This is further exacerbated in the formal and informal refugee camps that they move to, sometimes in neighboring countries. Refugee camps are often very crowded places, with living conditions strained by the very basic infrastructure available and the number of people needing to use it. Security in these situations is particularly a concern for women, children and other vulnerable groups such as people with disabilities (UNHCR The State of the World's Refugees).

Many of these issues and responses, beginning with dispossession, life in refugee camps and, for some, detention upon arrival in Australia, make migration patterns and settlement processes for refugees very different from those of other migrants (Brautigam). For many refugees the trials of settlement are all the more difficult and accentuated as they have passed through harrowing times before arrival in the new country (Babacan and Gopalkrishnan). Aroche and Coello argue that refugees face three kinds of challenges in their country of resettlement beginning with torture and trauma issues. The trauma experienced in the context of organized violence not only places individuals, families and communities in a vulnerable position in the host country but also interferes with their ability to access and utilize their internal resources to the fullest potential, placing refugees at great disadvantage in negotiating the complex demands of exile, migration and resettlement. Secondly refugees face exile, migration and resettlement issues. Exile and migration include all the security and health issues involved in movement, life in the refugee camps, helplessness and dependence as well as loss of support networks of friends and family. There is also a loss of connection to the external environment as well as the process of coping with this loss of connection as a form of mourning. This also leads to a loss of coherence with the internal map of reality and the external environment, leading to basic issues of identity (J. Aroche and M. J. Coello).

Resettlement also puts a number of stresses on the individual family and community, a phase characterized by the need for a steep learning curve while being impacted on by the diminished personal resources due to their lived experience. And finally refugees also face the normal life cycle stages and personality/ family issues: the refugee experience can make the normal life cycle stages difficult to negotiate, or vice-versa, where the normal life cycle stages may bring up issues related to the refugee experience. All of these issues in turn impact on the health of refugees (Aroche and Coello).

\section{The Health of Refugees}

The health problems experienced by refugees have been widely documented. Much of the language used in the literature is placed within the biomedical paradigm, with extensive 
separation between the so-called mental and physical elements of health and illness and the linear relationships of cause and effect (Tribe "The Mental Health Needs of Refugees and Asylum Seekers"; Feldmann et al.). The psychological effects of trauma experienced by refugees tend to be enduring and long-lasting (Silove). Some of these can be classified under cognitive, psychological and neurovegetative symptoms. Cognitive symptoms include disorientation, memory disturbance, impaired reading and poor concentration. Psychological symptoms include anxiety, depression, irritability, aggression, self-isolation and social withdrawal. Neurovegetative symptoms include lack of energy, insomnia, nightmares and sexual dysfunction. The range of problems can include depression, anxiety, guilt, loss of concentration and memory problems and many other issues that are often described as symptoms of posttraumatic stress disorder (PTSD) or more appropriately Complex PTSD (Nairn).

Clinical research in a number of studies demonstrates a high prevalence of posttraumatic stress and depression symptoms among refugees (Hollifield et al.). With regards to the commonly detected symptoms of PTSD among refugees, a note of caution is that symptomatic behavior of refugees are common psychological reactions to stress and need not necessarily be equated with those of a major mental illness requiring a psychiatric diagnosis (Lin). This is further affirmed by Moore who examined several examples of over-diagnosis of disorders such as schizophrenia and paranoia among specific ethnic groups (Moore).

Several scholars have pointed out that the lives of refugees in Australia are complicated by having to face negative and racist attitudes directed at them as also facing personal and institutional discrimination in the workplace (Colic-Peisker and Tilbury; VicHealth; CorreaVelez, Gifford and Barnett). An international review by the Victorian Health Promotion Foundation also points out to a strong link between self-reported discrimination and depression and anxiety, a probable link with a range of other mental health and behavioral problems and emerging evidence of a link with poor physical health, such as diabetes, obesity and high blood pressure (VicHealth).

The framework of practice in refugee health is largely within the dualistic biomedical paradigm involving a clear separation of physical and mental services. The physical health elements are catered to by hospitals, clinics and GPs while the mental health issues are managed through non-governmental organizations, psychiatrists and counselors (DIAC New Beginnings: Supporting New Arrivals on Their Settlement Journey 2006-2007; QH). This emphasis on the separation of physical and mental health systems in working with the health problems of refugees raises several issues.

While it is true that within any refugee population there are those who are severely traumatized and acutely mentally ill, the great majority are experiencing severe distress and suffering, conditions that can be managed using a host of other therapies and systems rather than psychiatry and medicine (WHO Mental Health of Refugees; NCTSN). As the World Health Organization states in the context of refugees in conflict and post-conflict situations:

...distress and suffering are not psychiatric illnesses. These reactions are normal (expected) reactions to extraordinary violent events and therefore generalized psychiatric care is inappropriate and must be prevented. (WHO Rapid Assessment of Mental Health Needs of Refugees, Displaced and Other Populations Affected by Conflict and Post-Conflict Situations 1) 
The process of forced migration that refugees undergo almost always involves moving between cultures, and the final resettlement involves settling into a culture that is often quite different from their own. This has many implications in terms of the health and illness of refugee populations (NCTSN; Chung et al.). Culture influences our understanding of health and illness, modes of treatment as well as health-seeking behavior such as attitudes to preventative and curative care, attitudes to providers as well as expectations of the healthcare system (Murray and Skull; VFST).

When we look at the social construction of health and illness, there is significant evidence to show that culture plays a major role in how we understand health and illness and that there are significant differences in cultural understandings of these (Babacan and Gopalkrishnan; Fenta, Hyman and Noh). Research conducted by Feldman et al. with Afghan refugees in the Netherlands found that most of the participants made no distinction between what Western medicine refers to as 'mental' and 'physical' health. Further, an immediate connection seemed to be made between health and 'autonomy' in the sense of being able to look after yourself and those who depend on you (Feldmann et al.). These views are also substantiated by research with Ethiopian refugees in the UK which showed that their perception of health were that 'health is happiness and happiness is health', where health referred to having harmonious relationships, fulfillment of dreams, not being depressed, stressed or worried and being physically fit and not suffering illness (Papadopoulos et al.).

The causes of disease can be viewed differently across cultures, such as due to possession by ancestral spirits, imbalance between yin and yang in traditional Chinese medicine, imbalance between Vata, Pitta and Kapha in Ayurveda, failure to be in harmony with nature, the 'evil eye', being out of balance, and breaking of taboos (Culhane-Pera, Her and Her; Kline and Huff; Papadopoulos et al.). This plurality of views of health is supported by Helman who presents a model of illness causality that ranges across from the individual, the natural world, the social world and argues that every illness has multiple causes and every cultural group would perceive these differently (Helman). Many Western approaches tend to be 'predicated on a model that focuses on individual intrapsychic experience or individual pathology, while other traditions may be based more on community or familial processes' (Tribe "The Mental Health Needs of Refugees and Asylum Seekers" 8).

These barriers to effective healing may also be impacted on by the power relationship between the cultures of the therapist and the patient. While culture performs an integrative function, bringing together people within a group, it also excludes people who do not adhere to these norms and values. In the context of health systems, this exclusionary aspect of culture begins to play a very significant role in the experience of ill health as well as in treatment especially given a history of power differentials and ideologies that are part of the colonization process in many countries. An example may be taken of the issues of refugee mental health where 'culture is both the cause of this pain as well as the pathway to recovery' (J. Aroche and M. J. Coello 55). On the one hand, the patient's attitude towards his/her illness is built around a conglomeration of ethno cultural beliefs and values, personal beliefs, values and behaviors and an understanding of biomedical concepts. This then interacts with the therapist's culture within the clinical encounter.

In Australia, as with many other industrially developed countries, most therapists, including those who work with refugees, espouse Western systems of therapy (Wilson and Drozdek) that have evolved within the political contexts in Western countries, often within a colonial framework. In the context of working across cultures, this background involves the therapist dealing with some of his or her own assumptions and resultant behaviors before a helping 
relationship can be established. Many of the assumptions around normality and psychopathology that are core to Western therapy are culturally embedded in Western, middleclass constructions and have questionable cross-cultural generalizability (NCTSN). Cultural bias and stereotyping can impact negatively on the therapeutic relationship and process. As Kline and Huff (7) argue, cultural differences present major barriers to effective health care interventions especially when 'health practitioners overlook, misinterpret, stereotype, or otherwise mishandle their encounters with those who might be viewed as different from them in their assessment, intervention, and evaluation-planning processes'.

Culture also impacts on how therapies and treatments are viewed. Kidson (39) cites a Vietnamese health worker who, in her experience, believes that many Vietnamese refugees see psychiatry/psychology as 'rubbish' and that talking and using tablets are of no use for their complaints. This view is not uncommon as 'talking about painful events may not be experienced as valuable or therapeutic by refugees from societies in which psychological models are not hegemonic' (NCTSN 32). Sypek et al. also reflect on several cases where differences of perception of treatment between refugees and GPs in rural and regional towns lead to a mismatch of expectations, and attendant conflict (Sypek, Clugston and Phillips).

In the biomedical systems in place to work with the issues of refugees in countries like Australia and the United States, there is an emerging understanding of many of the culturally different approaches to health and illness (Ong; Singer). The accommodation of these, however, is mainly in the form of reading the symptoms and using the patient's cultural beliefs to present universalized states of biomedicine as:

[b]y controlling the medical terms and practices, and seeking to instill them in patients, academic and medical workers are part of an overall scheme of power that defines the form and content of refugee illness and well-being, while producing the truth-effects that shape the subjectivities of Southeast Asian immigrants. Overworked and under-funded clinics, swamped with clients from all over the world, seek an efficient, though unsatisfactory, strategy to reduce the multicultural and personal details of patients' illnesses into diagnostic categories, so that they can dispense drug treatment. (Ong 1247)

The literature suggests that the more health services are sensitive to their clients' cultural and linguistic backgrounds, the better are the chances of improved access and equity, health literacy, communication, patient safety and quality of service provision as well as improved health encounters and outcomes through building trust and ensuring follow up (Lamb and Cunningham; Woodland et al.). The formal health services, especially those that provide biomedical services after the initial settlement period of six months, continue to be accessed at a relatively low level by refugees (Correa-Velez et al.; Fenta, Hyman and Noh). Both hospitals and general practitioners can prove to be major hurdles for refugees in accessing health services if they are not culturally relevant and working through a multiplicity of approaches while dealing with the health of refugees (Tribe "Health Pluralism: A More Appropriate Alternative to Western Models of Therapy in the Context of the Civil Conflict and Natural Disaster in Sri Lanka?"; Feldmann et al.).

\section{Art as Complementary and Alternative Medicine (CAM) and the Health of Refugees}

Western nations, such as Australia, used to consider the work of many of the approaches other than biomedicine as legitimate and authoritative until the beginning of the twentieth century, and the Flexner report of 1910, which led to the delegitimization and marginalization 
of all non-biomedical approaches (Steuter; WHCCAMP). However, while biomedicine has remained the dominant paradigm in the 20th and 21st Centuries, many of the other medical systems often referred to as Complementary and Alternative Medicine (CAM), have experienced a new resurgence in terms of their popularity and usage (Bodeker 2007). Many of these terms used to describe these systems are ideological constructs that place negative connotations on the therapies in relation to the 'scientific, rational world' of biomedicine (Ernst). The following definition moves beyond these to place the discussion in the arena of historical power relations.

Complementary and alternative medicine (CAM) is a broad domain of healing resources that encompasses all health care systems, modalities, and practices and their accompanying theories and beliefs other than those intrinsic to the politically dominant health care of a particular society or culture in a given historic period. CAM includes all such practices and ideas self-defined by their users as preventing or treating illness or promoting health and well-being. Boundaries within CAM and between the CAM domain and the domain of the dominant system are not always sharp or fixed. (OAM 1997 cited in Kopelman 37)

Art therapy is one such CAM approach that has clear significance in terms of working with the health of refugees (Kalmanowitz; Baker). The term 'art' is used in its broadest sense, including music, dance, craft, drama, writing and the visual arts, all of which express and symbolize what cannot be said in words (Fitzpatrick 152). Many scholars prefer to differentiate between art therapy as a professional discipline and art as a therapeutic activity, mainly because of the training and professional backgrounds of art therapists as related to the more accessible therapeutic activity of art (Stickley and Duncan; Griffiths). In the context of this paper however, the term 'art therapy' is being used to refer to both the professional aspect of art therapy as well as the more generic notions of art as a therapeutic activity, so as to consider the benefits from both these aspects of art activity.

There are several key areas in which CAMs like art therapy differ from traditional biomedical approaches in dealing with health issues, differences that often provide the reasons why people resort to CAMs for treatment. Firstly, biomedicine works within a framework of cause and effect, a linear process of pathogen-illness and treatment. CAM practitioners, on the other hand, largely view the patient and the 'illness' from a holistic point of view not restricted to an external pathogen (Shuval; Guinn). This entails looking at the different areas that impact on the health and illness of the person including the body, the psychosocial, the environmental and the social-cultural (Libster). They are often able to provide support, care and healing for those with chronic illnesses, even those where the causes cannot be pinpointed, because of this holistic approach (Jonas and Levin). This is of particular significance in terms of art as therapy working with refugees, as the trauma they have experienced manifests in a range of symptoms that do not fit into the pathogen/illness process (Gopalkrishnan). Art therapy enables the survivors of trauma to create a visual dialogue and thereby resolve conflict, develop personal strengths and heal their invisible wounds without necessarily looking for a single source of these issues (Baker).

The second area is that of power relationships developed in the process. In biomedicine, the doctor retains power, using different tools to fix the illness in the patient. The patient is only a biological machine to be acted upon (Mino and Lert). While CAM practitioners like professional art therapists are also experts in their own fields, they tend to act within a more equal, power-sharing relationship, enabling the patients to be active within their own healing 
process (Gaydos; Shuval). Also, most CAM approaches adopt the view that the relationship of the practitioner and the patient is central to a positive outcome (Gaydos). To people who are looking for a sustained healing partnership rather than a brief consultation, as well as selfempowerment, CAMs are increasingly providing a viable alternative to biomedicine (WHCCAMP; VFST). (Eaton, Doherty and Widrick), point to this aspect of healing in their literature review of art therapy as a treatment regime for traumatized children, including young refugees, concluding that art therapy is an effective tool for the establishment of healing relationships between children and therapists.

The third area is where the biomedical practitioners tend to work within an illness paradigm, where the doctor is either treating illness or trying to avoid it in some form. CAM practitioners on the other hand tend to be more focused on nurturing the health of the patient, treating health as the norm, and health enhancement as the goal, being proactive in addressing lifestyle factors and early warning signs (Guinn). Alternative therapies such as Yoga and Tai Chi, among others, enable a more holistic approach to health as more than 'being ill'. They examine five major areas of health enhancement; a) stress management; b) spirituality and meaning issues; c) dietary and nutritional counseling; d) exercise and fitness; and e) addiction or habit management (Jonas and Levin). This view is supported by Cohen who suggests that conventional Western medicine appears to concentrate on moving people across from the division between ill health to average health, while complementary medicine seems to concentrate on moving people across the division between average levels of health to enhanced health (Cohen). While art therapy does not have the span of interventions of systems like Traditional Chinese Medicine and Ayurveda, it generates a range of benefits that include enhanced self-esteem, expression of feelings, development of problem-solving and conflict resolution skills and improved mood and physical well-being (Rousseau and Heusch; Greaves and Farbus).

CAM therapies also enable room for traditional spiritual and cultural practices (Jonas and Levin). Illness, mental or physical, is only one part of a larger cultural schema that explains important moral and social questions. The theoretical and philosophical foundations of CAM therapies support integration of the body, mind and spirit and view the person within social and cultural contexts (Gaydos 2001). Art therapy can play an important role in this context as the use of the arts as tools of healing and communication has a special role to play in many cultures including fostering rites of passage and making connections with the spiritual (Crumlin \& Knight 1991 cited in Fitzpatrick 152). Griffiths points to research with African and Caribbean men in the United Kingdom, where art therapy enabled the participants to establish their cultural identity as well as protected them from the negative effects of racism and discrimination that they faced on a daily basis (Griffiths 29). These findings present important ramifications for the inclusion of art therapy in working with the health of refugees in Australia, as racism and discrimination have significant impacts on the successful settlement of refugees, as discussed earlier in the paper. Art therapy is actually preferred in some cultures as against other CAMS because they can provide connections to home, familiarity and social connections (Gopalkrishnan 185-86; Baker). Traditional crafts like needlework and quilting can reconnect a person to their own cultures, develop old skills and learn new ones as well as build social networks (Baker 187)

Many refugees in Australia come from countries that have a tradition of indigenous medicine, and the ability to access similar traditions in Australia can provide affirmation and empowerment, as well as acting as a bridge between the two cultures (Papadopoulos et al.; Gopalkrishnan). Many refugees are used to working with a plurality of healing modalities 
including biomedicine in their home countries, and the dominance of the biomedicine within the formal health structures that they face in Australia may be inadequate to deal with their complex health issues (Culhane-Pera, Her and Her; Fenta, Hyman and Noh). CAMs involving meditation, massage and relaxation can provide a gentle non-invasive way of dealing with some of the symptoms of trauma such as chronic pain, breathing difficulties, anxiety, depression and stress, and the tactile elements can help to build trust in touch, an element very important to survivors of trauma (FASSTT). Nonverbal expressive therapies, such as art therapy, have an important place in treating victims of trauma, such as refugees and survivors of child abuse, since they are especially designed to engage with implicit consciousness and implicit memories. Art, music, yoga and movement therapies have added advantages when therapist and patient do not share a common spoken language (Wilson and Drozdek; FASSTT).

There is a body of evidence that demonstrates the increasing utilization of medical plurality and CAM across the world as presented in this table:

Table 1: Utilization of Complementary and Alternative Medicine (CAM) Systems in some countries

\begin{tabular}{|l|l|l|l|}
\hline Country & $\begin{array}{l}\text { Utilization (percentage } \\
\text { of population })^{1}\end{array}$ & Country & $\begin{array}{l}\text { Utilivation(percentage } \\
\text { of population })^{1}\end{array}$ \\
\hline Australia & 48 & France & 49 \\
\hline Canada & 70 & Germany & 75 \\
\hline Chile & 71 & Israel & 9.8 \\
\hline China & 40 & Pakistan & 51.7 \\
\hline Colombia & 40 & United Kingdom & 47 \\
\hline Denmark & 33 & United States & $62 / 36^{2}$ \\
\hline
\end{tabular}

${ }^{\mathrm{I}}$ The survey years in each country varies from 1994 to 2002 depending on the source of the data

${ }^{2} 62$ per cent included prayer for health reasons: 36 per cent when prayer was excluded (Eisenberg. 1569; Shuval and Mizrachi 678; Bodeker 8; Shaikh et al. 547)

Complementary therapies have also become accepted among biomedical practitioners, with over 80 per cent of the GPs surveyed in one research project indicating that they have referred patients for a complementary therapy at least a few times a year (Cohen et al.) while another survey of 300 family physicians in New England found 90 per cent considered complementary therapies legitimate and most respondents desired training in complementary therapies themselves (Clark). A comprehensive review of 25 surveys of physicians and their practices and beliefs around five CAM practices found that half the surveyed physicians believed that these practices were useful or efficacious (Astin et al.). Even the Australian Medical Association (AMA) uses carefully worded phrases to acknowledge the growing recognition of the effectiveness of CAMs and concluding by recognizing that evidence-based aspects of Complementary Medicine are part of the repertoire of patient care and may have a role in mainstream medical practice. David Hufford reflects on the irony of this in the context of migrants and refugees, saying: 
Physicians are urged to be respectfully aware of the "ethnocultural health beliefs and behaviors"- the CAM beliefs and practices- of the least-assimilated members of immigrant groups, assuming that with time these patients will become "more like mainstream patients". At the same time, their colleagues are documenting the widespread use of CAM among "mainstream patients". (27)

In terms of the health of refugees in Australia, a significant number of specialized agencies that work specifically with the survivors of torture and trauma (almost all refugees) utilize a multilevel approach involving biomedicine, counseling and including complementary medicine and therapy. While the trauma services program is primarily funded to work with the mental health issues of refugees using biomedical practitioners and counselors, many of the state bodies have incorporated complementary and alternative medicines as part of their services, often drawing on the services of unpaid volunteers to provide them. Table 2 presents the details of the CAM services that are being, or have been provided to refugee groups by the trauma services across Australia.

Table 2: Provision of CAM therapies in Trauma Services in Australia

\begin{tabular}{|c|c|c|}
\hline State & Organization & CAMs and related activities \\
\hline Victoria & $\begin{array}{l}\text { The Victorian Foundation for } \\
\text { the Survivors of Torture } \\
\text { (Foundation House) }\end{array}$ & Yoga, massage therapy, herbal medicine. \\
\hline $\begin{array}{l}\text { New South Wales } \\
\text { (NSW) }\end{array}$ & $\begin{array}{l}\text { NSW Service for the Treatment } \\
\text { and Rehabilitation of Torture } \\
\text { and Trauma Survivors } \\
\text { (STARTTS) }\end{array}$ & $\begin{array}{l}\text { Yoga, acupuncture, neurofeedback, activity } \\
\text { groups for exercise, crafts, support, } \\
\text { psychoeducation and therapeutic groups. }\end{array}$ \\
\hline Queensland & $\begin{array}{l}\text { Queensland Program of } \\
\text { Assistance to Survivors of } \\
\text { Torture and Trauma (QPASTT) }\end{array}$ & $\begin{array}{l}\text { Nutrition therapy, herbal medicine, } \\
\text { homeopathy, yoga, massage, aromatherapy } \\
\text { and flower essences }\end{array}$ \\
\hline Northern Territory & $\begin{array}{l}\text { Torture and Trauma Survivors } \\
\text { Service of the Northern } \\
\text { Territories (Melaleuca Refugee } \\
\text { Centre) }\end{array}$ & $\begin{array}{l}\text { Narrative therapies, play therapy, creative } \\
\text { arts therapy and dance movement therapy. }\end{array}$ \\
\hline Western Australia & $\begin{array}{l}\text { Association for Services to } \\
\text { Torture and Trauma Survivors } \\
\text { (ASeTTS) }\end{array}$ & Massage therapy \\
\hline South Australia & $\begin{array}{l}\text { Survivors of Torture and } \\
\text { Trauma Assistance and } \\
\text { Rehabilitation service } \\
\text { (STTARS) }\end{array}$ & Remedial massage \\
\hline $\begin{array}{l}\text { Australian Capital } \\
\text { Territory }\end{array}$ & $\begin{array}{l}\text { Companion House (Assisting } \\
\text { Survivors of Torture and } \\
\text { Trauma) }\end{array}$ & Bowen therapy and Bach flower remedies. \\
\hline Tasmania & Phoenix Centre & $\begin{array}{l}\text { Massage therapy, relaxation exercises, } \\
\text { reflexology, medicinal herbal teas and } \\
\text { lifestyle/nutritional advice. }\end{array}$ \\
\hline
\end{tabular}

(FASSTT; QPASTT; DIAC New Beginnings: Supporting New Arrivals on Their Settlement Journey 2006-2007) 
Anecdotally, the level of government funding for these alternative services is minimal or nonexistent, with money often being used from core funds or sponsorships by corporate entities or else by the widespread support of volunteer health practitioners (Roxon). One NGO refers to the paucity of funding by stating that its natural therapies program is limited and only available to those of their clients most in need of them, a point that is emphasized by the fact that their Natural Therapies program was discontinued prior to their 2009 annual report (QPASTT; QPASTT). The fact that, despite the lack of formal support by the Federal Government, CAM approaches continue to be incorporated into the programs of these organizations points to the benefits experienced by the refugee clients of these organizations.

\section{Conclusion}

The biomedical paradigm presents us with a range of issues in terms of the health of refugees; issues involving the understanding of health and illness, causality and healing, issues of the mind/body duality, reductionism and lack of complexity, power relationships and structures, all of which indicate the need for a framework that better accommodates difference. Scholars have suggested that holistic approaches that address all the needs of refugees - physical, mental, spiritual, environmental and social-cultural, incorporating a multiplicity of systems that include community-based health systems as well as other interventions like art, drama, music and other complementary and alternative therapies would be culturally appropriate as well as providing choice to refugees (Papadopoulos et al.; NCTSN; Woodland et al.). Multidisciplinary and multi-pronged approaches that work together to address all the major factors impacting on the health of refugees at various levels of the system are likely to be more effective than the present dependence on the biomedical paradigm. Art therapy presents as one of the disciplines that can work together with biomedicine and other CAM approaches synergistically to provide optimum benefits to refugees struggling with the effects of trauma. As a therapeutic approach, art provides a range of possible benefits that go beyond the illness paradigm and it can work toward a state of enhanced good health for refugees. It can enable the development of effective therapeutic relationships even where there are language barriers. Further it can respond effectively to the spiritual and cultural needs of refugees of diverse backgrounds. With the increasing acceptance of CAM approaches in countries such as Australia, there is a strong case to be made on the broad adoption of art therapy as one of the key approaches supporting the health needs of refugees. 


\section{Works Cited}

AMA. "Complementary Medicine". 2002. Australian Medical Association. 16/3/2009 2009. <http://ama.com.au/node/2214>.

Aroche, J. , and M. J. Coello. "Ethnocultural Considerations in the Treatment of Refugees and Asylum Seekers." Broken Spirits: The Treatment of Traumatized Asylum Seekers, Refugees, and War and Torture Victims. Eds. Wilson, J. P. and B. Drozdek. New York.: Routledge, 2004. 53-80. Print.

Aroche, J., and M. J. Coello. Towards a Systematic Approach for the Treatment Rehabilitation of Torture and Trauma Survivors in Exile. Sydney: STARTTS, 2002. Print.

Astin, John A., et al. "A Review of the Incorporation of Complementary and Alternative Medicine by Mainstream Physicians." Arch Intern Med.158 (1998): 2303-10. Print.

Babacan, Hurriyet, and Narayan Gopalkrishnan. "Post Traumatic Experiences of Refugee Women." Understanding Gender and Culture in the Helping Process. Ed. Rabin, C. . USA: Wadsworth Group Thomson Learning, 2005. 149-66. Print.

Baker, Barbara Ann. "Art Speaks in Healing Survivors of War." Journal of Aggression, Maltreatment \& Trauma 12.1-2 (2006): 183-98. Print.

Bodeker, Gerry. "Global Trends in Natural Healthcare." Integrative Medicine Perspectives. Ed. Cohen, Marc. Melbourne: AG Publishing, 2007. 6-26. Print.

Brautigam, C. A. . "Traumatized Women." International Responses to Traumatic Stress. Eds. Daneili, Y., N.S. Rodley and L. Weisaeth. New York: Baywood Publishing Company, 1996. 347-66. Print.

Chung, Rita Chi-Ying, et al. "Promoting the Mental Health of Immigrants: A Multicultural/Social Justice Perspective." Journal of Counseling \& Development. 86 (2008): 310-17. Print.

Clark, Carolyn Chambers. Integrating Complementary Health Procedures into Practice. New York: Springer Publishing Company, 2000. Print.

Cohen, M., et al. "The Integration. Of Complementary Therapies in Australian General Practice: Results of a National Survey." The Journal of Alternative and Complementary Medicine 12.8 (2006): 707-08. Print.

Cohen, Marc. "Introduction." Holistic Healthcare in Practice. Ed. Cohen, Marc. Clayton, Vic: Australasian Integrative Medicine Association, 2003. 1-4. Print.

Colic-Peisker, V., and F. Tilbury. "Integration into the Australian Labour Market: The Experience of Three 'Visibly Different' Groups of Recently Arrived Refugees." International Migration Review 45.1 (2007): 59-85. Print.

Correa-Velez, Ignacio, Sandra M. Gifford, and Adrian G. Barnett. "Longing to Belong: Social Inclusion and Wellbeing among Youth with Refugee Backgrounds in the First Three Years in Melbourne, Australia." Social Science \& Medicine.71 (2010): 1399408. Print. 
Correa-Velez, Ignacio, et al. "Hospital Utilisation among People Born in Refugee-Source Countries: An Analysis of Hospital Admissions, Victoria, 1998-2004." MJA 186.11 (2007): 577-80. Print.

Culhane-Pera, Kathleen A., Cheng Her, and Bee Her. ""We Are out of Balance Here": A Hmong Cultural Model of Diabetes." J Immigrant Minority Health.9 (2007): 179-90. Print.

DIAC. Australia's Humanitarian Program 2013-2014 and Beyond. Canberra: Department of Immigration and Citizenship, 2012. Print.

---. New Beginnings: Supporting New Arrivals on Their Settlement Journey 2006-2007. Canberra: Department of Immigration and Citizenship, 2008. Print.

Eaton, Leslie G., Kimberly L. Doherty, and Rebekah M. Widrick. "A Review of Research and Methods Used to Establish Art Therapy as an Effective Treatment Method for Traumatized Children." The Arts in Psychotherapy 34.3 (2007): 256-62. Print.

Eisenberg., D. M. "Trends in Alternative Medicine Use in the United States from 1990-1997 Results of a Follow-up Study." JAMA 280.18 (1998): 1569-75. Print.

Ernst, Waltraud. "Plural Medicine, Tradition and Modernity." Plural Medicine, Tradition and Modernity, 1800-2000. Ed. Ernst, Waltraud. London: Routledge, 2002. Print.

FASSTT. Out of the Abyss: Australia's Program of Assistance to Survivors of Torture and Trauma. Brunswick: Forum of Australian Services for Survivors of Torture and Trauma, 2006. Print.

Feldmann, C. Titia, et al. "Afghan Refugees and Their General Practitioners in the Netherlands: To Trust or Not to Trust?" Sociology of Health \& Illness 294 (2007): 515-35. Print.

Fenta, Haile, Ilene Hyman, and Samuel Noh. "Health Service Utilization by Ethiopian Immigrants and Refugees in Toronto." J Immigrant Minority Health.9 (2007): 34957. Print.

Fitzpatrick, Fiona. "A Search for Home: The Role of Art Therapy in Understanding the Experiences of Bosnian Refugees in Western Australia." Art Therapy: Journal of the American Art Therapy Association 19.4 (2002): 151-58. Print.

Gaydos, H.L. "Complementary and Alternative Therapies in Nursing Education: Trends and Issues". 2001. Online Journal of Issues in Nursing May 2001: 16/1/2011 2011. <www.nursingworld.org/MainMenuCategories/ANAMarketplace/ANAPeriodicals/O JIN/TableofContents/Volume62001/No2May01/TrendsandIssues.aspx>.

Gopalkrishnan, N. "Yoga Therapy and the Health of Refugees." Curtin University, 2012. Print.

Greaves, C. J., and L. Farbus. "Effects of Creative and Social Activity on the Health and Well-Being of Socially Isolated Older People: Outcomes from a Multi-Method Observational Study." Journal of the Royal Society for the Promotion of Health 126.3 (2006): 134-42. Print. 
Griffiths, Sandra. "The Mental Health Benefits of Arts and Creativity for Young African and Caribbean Men." The Mental Health Review 10.2 (2005): 27-31. Print.

Guinn, David E. "Ethics and Integrative Medicine: Moving Beyond the Biomedical Model." Alternative Therapies in Health and Medicine 7.6 (2001): 68-72. Print.

Helman, C. G. Culture, Health and Illness. 5 ed. London: Hodder Arnold, 2007. Print.

Hollifield, M., et al. "Measuring Trauma and Health Status in Refugees." JAMA 288.5 (2002): 611-21. Print.

Hufford, David J. "Cam and Cultural Diversity: Ethics and Epistemology." The Role of Complementary and Alternative Medicine: Accomodating Pluralism. Ed. Callahan, Daniel. Washington: Georgetown University Press, 2002. 15-35. Print.

Jonas, Wayne B., and Jeffrey S. Levin. "Introduction: Models of Medicine and Healing." Essentials of Complementary and Alternative Medicine. Eds. Jonas, Wayne B. and Jeffrey S. Levin. Baltimore: Lippincort Williams and Wilkins, 1999. 1-16. Print.

Kalmanowitz, Debra. "Fragments of Art at Work: Art Therapy in the Former Yugoslavia." The Arts in Psychotherapy 26.1 (1999): 15-25. Print.

Kidson, Stephen. "Exploratory Study on the Needs of Refugee Survivors of Torture and Trauma in South Australia." Australian Social Work 46.4 (1993): 35-40. Print.

Kline, Michael V., and Robert M. Huff. "Health Promotion in the Context of Culture." Health Promotion in Multicultural Populations. Eds. Kline, Michael V. and Robert M. Huff. Thousand Oaks: Sage, 2007. 3-22. Print.

Kneebone, Susan, and Pascale Allotey. "Refugee Health, Humanitarianism, and Human Rights." The Health of Refugees: Public Health Perspectives from Crisis to Settlement. Ed. Allotey, Pascale. New York: Oxford University Press, 2003. 1-13. Print.

Kopelman, Loretta M. "Role of Science in Assessing Cam." The Role of Complementary and Alternative Medicine: Accomodating Plurality. Ed. Callahan, Daniel. Washington: Georgetown University Press, 2002. 36-53. Print.

Lamb, Cath Finney, and Margaret Cunningham. "Dichotomy or Decision Making: Specialisation and Mainstreaming in Health Service Design for Refugees." The Health of Refugees: Public Health Perspectives from Crisis to Settlement. Ed. Allotey, P. Melbourne: Oxford University Press, 2003. 123-38. Print.

Libster, Martha. Demonstrating Care: The Art of Integrative Nursing. Albany: Delmar, 2001. Print.

Lin, K. M. . "Psychopathology and Social Disruption in Refugees." Refugee Mental Health in Resettlement Countries. Eds. Williams, C. L. and J. Westermeyer. Washington DC: Hemisphere, 1986. 61-73. Print.

Mino, J-C., and France Lert. "Beyond the Biomedical Model: Palliative Care and Its Holistic Model." HEC Forum 17.3 (2005): 227-36. Print. 
Moore, L. J. "Psychiatric Contributions to Understanding Racism." Transcultural Psychiatry Vol. 37 (2) Ed. Kirmayer, L. America: SAGE Publications, 2000. 147-82. Print.

Murray, Sally B., and Sue A. Skull. "Hurdles to Health: Immigrant and Refugee Health Care in Australia." Australian Health Review 29.1 (2005): 25-29. Print.

Nairn, R. Notes on Health and Mental Health for Asylum Seekers and Refugees Held in Immigration Detention Centres and Living in the Community. Canberra: Refugee Action Committee, 2005. Print.

NCTSN. "Review of Child and Adolescent Refugee Mental Health White Paper". 2005. National Child Traumatic Stress Network Refugee Trauma Task Force

14 April 2008. < Error! Hyperlink reference not valid..

Ong, Aihwa. "Making the Biopolitical Subject: Cambodian Immigrants, Refugee Medicine and Cultural Citizenship in California." Social Science \& Medicine 40.9 (1995): 124358. Print.

Papadopoulos, Rena, et al. "The Impact of Migration on Health Beliefs: The Case of Ethiopian Refugees in the Uk." Contemporary Nurse.15 (2003): 210-22. Print.

QH. Queensland Refugee Health Service Service Plan. Ed. Health, Queensland. Brisbane: Queensland Government, 2008. Print.

QPASTT. Annual Report. Brisbane: Queensland Programme of Assistance to Survivors of Torture and Trauma, 2006. Print.

---. Annual Report. Brisbane: Queensland Program of Assistance to Survivors of Torture and Trauma, 2009. Print.

Rousseau, Cécile, and Nicole Heusch. "The Trip: A Creative Expression Project for Refugee and Immigrant Children." Art Therapy: Journal of the American Art Therapy Association 17.1 (2000): 31-40. Print.

Roxon, Sue. "Regaining the 'Life Force'". Sydney, 2007. STARTTS. 12/4/10 2010. $<$ http://www.startts.org.au/default.aspx?id=237>.

Shaikh, Shahzad H., et al. "Trends in the Use of Complementary and Alternative Medicine in Pakistan: A Population-Based Survey." The Journal of Alternative and Complementary Medicine 15.5 (2009): 545-50. Print.

Shuval, J.T., and N. Mizrachi. "Changing Boundaries: Modes of Co-Existence of Alternative and Bio-Medicine " Qualitative Health Research 14.5 (2004): 675-90. Print.

Shuval, Judith. "Nurses in Alternative Health Care: Integrating Medical Paradigms." Social Science \& Medicine.63 (2006): 1784-95. Print.

Silove, D. . "The Psychosocial Effects of Torture, Mass Human Rights Violations and Refugee Trauma." Journal of Nervous and Mental Disease.187 (1999): 200-07. Print.

Singer, J. B. "Listening to Refugee Bodies: The Naturopathic Encounter as a Cross-Cultural Meeting Place." Southern Cross 2008. Print. 
Steuter, Erin. "Contesting the Rule(S) of Medicine: Homeopathy's Battle for Legitimacy." Journal of Canadian Studies 37.3 (2002): 12-16. Print.

Stickley, Theodore, and Kate Duncan. "Art in Mind: Implementation of a Community Arts Initiative to Promote Mental Health." Journal of Public Mental Health 6.4 (2007): 2432. Print.

Sypek, Scott, Gregory Clugston, and Christine Phillips. "Critical Health Infrastructure for Refugee Resettlement in Rural Australia: Case Study of Four Rural Towns." Aust. J. Rural Health.16 (2008): 349-54. Print.

Tribe, Rachel. "Health Pluralism: A More Appropriate Alternative to Western Models of Therapy in the Context of the Civil Conflict and Natural Disaster in Sri Lanka?" Journal of Refugee Studies 20.1 (2007): 21-36. Print.

---. "The Mental Health Needs of Refugees and Asylum Seekers." The Mental Health Review 10.4 (2005): 8-15. Print.

UNHCR. Convention and Protocol Relating to the Status of Refugees. Geneva: United Nations High Commissioner for Refugees, 2007. Print.

---. The State of the World's Refugees. United Nations High Commissioner for Refugees, 2005. Print.

---. Unher Statistical Yearbook. Geneva: United Nations High Commissioner for Refugees, 2011. Print.

VFST. "Promoting Refugee Health". Melbourne, 2007. Victorian Foundation for Survivors of Torture. 19/2/2010 2010.

<www.foundationhouse.org.au/LiteratureRetrieve.aspx?ID=25035>.

VicHealth. Ethnic and Race-Based Discrimination as a Determinant of Mental Health and Wellbeing. Ed. Foundation, Victorian Health Promotion. Melbourne2007. Print.

WHCCAMP. Final Report. Maryland: White House Commission on Complementary and Alternative Medicine Policy, 2002. Print.

WHO. Mental Health of Refugees. Geneva: World Health Organization, 1996. Print.

---. Rapid Assessment of Mental Health Needs of Refugees, Displaced and Other Populations Affected by Conflict and Post-Conflict Situations. Geneva: World Health Organization, 2000. Print.

Wilson, J., and B. Drozdek. Broken Spirits: The Treatment of Traumatized Asylum Seekers, Refugees, and War and Torture Victims New York: Routledge, 2004. Print.

Woodland, Lisa, et al. "Health Service Delivery for Newly Arrived Refugee Children: A Framework for Good Practice." Journal of Paediatrics and Child Health 46 (2010): 560-67. Print. 